\title{
The Relationship of Chemical Modification of Membrane Proteins and Plasma Lipoproteins to Reduced Membrane Fluidity of Erythrocytes from Diabetic Subjects
}

\author{
By C. Watala ${ }^{1}$ and P. D. Winocour ${ }^{2}$ \\ 1 Department of Biophysics, Medical University of Lodz, Poland \\ ${ }^{2}$ Department of Pathology, McMaster University, Hamilton, Ontario, Canada
}

(Received January 6/May 11, 1992)

\begin{abstract}
Summary: The significance of the two most common hallmarks of the diabetic state, hyperglycaemia and hyperlipidaemia, was investigated in terms of disorders of cell membrane dynamics. In order to examine whether the alterations in cell membrane lipid bilayer dynamics are somehow related to protein chemical modifications in plasma low- (LDL) and high-density lipoproteins (HDL) and blood cell membranes, we compared 19 poorly controlled diabetic subjects with 19 age- and sex-matched controls. The extent of (nonenzymatic) glycation, lipid peroxidation and the cholesterol/phospholipid ratio were increased in plasma low density lipoproteins and high density lipoproteins from diabetic patients. The mean steady-state fluorescence polarization values in 1,6-diphenyl-1,3,5-hexatriene-labelled isolated erythrocyte membranes from diabetic subjects were significantly greater than from control subjects $(0.186 \pm 0.008$ vs $0.173 \pm 0.006, p<0.001)$; the fluorescence polarization values in erythrocyte membranes from diabetic and control subjects positively correlated with the extent of membrane protein glycation, lipid peroxidation and the cholesterol content. The cholesterol to phospholipid molar ratios in low density lipoproteins and high-density lipoproteins from diabetic and control subjects correlated significantly with the fluorescence polarization values in erythrocyte membranes from these subjects. Furthermore, the extent of glycation of low density lipoproteins appears to be strongly correlated with the extent of lipoprotein lipid peroxidation $(r=0.789, p<0.001)$.
\end{abstract}

The atherosclerotic potential of plasma lipoproteins in diabetes mellitus was discussed in terms of membrane and plasma protein chemical modifications.

\section{Introduction}

Elevated plasma cholesterol concentrations and disturbed lipid metabolism are major risk factors in the pathogenesis of atherosclerosis and its thromboembolic complications in both the diabetic and nondiabetic populations (1). The concept that altered low density lipoproteins may have a role in the pathogenesis of atherosclerosis has emerged as a consequence of recent advances in our understanding of the mechanism involved in the interactions of lipoproteins with cells $(2,3)$. As a result of these interactions, a rapid change in cell membrane composition, particularly with regard to cholesterol, phospholipid, and fatty acid content, might occur, leading to alterations in membrane lipids and enzyme activities (4). Changes in erythrocyte membrane lipids and fluidity appear to be major determinants in erythrocyte elasticity and deformability (5). However, the relation between membrane-associated alterations and the formation of atherosclerotic lesions remains unclear. There is increasing evidence which indicates that non-enzymatic glycation of various proteins is an important molecular event in the diabetic state (6). There is also evidence to support the idea that many of the complications of diabetes result from hyperglycaemia (7). The observation that post-translational non-enzy- 
matic glycation of proteins can occur under physiological conditions has indicated that this could be at least one mechanism through which hyperglycaemia could lead to alterations in protein structure $(8,9)$. Increased non-enzymatic glycation of plasma lipoproteins has been implicated in the aetiology of several complications in diabetes mellitus, including vascular disease $(2,10,11)$. Other chemically or biologically modified low density lipoproteins are also poorly recognized by the low density lipoprotein receptor (11).

Recently, there has been increased interest in the idea that low density lipoproteins modified by oxidation may contribute to some of the changes associated with the formation of the atherosclerotic plaque. Several of the functional changes reported to occur when low density lipoproteins become oxidized indicate a possible role for oxidized low density lipoproteins in various pathological conditions $(10,11)$. The nonenzymatic glycation was correlated with the impaired dynamic properties of erythrocyte and platelet membranes from diabetic subjects $(12,13)$. Although their increased non-enzymatic glycation in diabetes is well recognized $(7,9,10,12,13)$, the evidence that oxidation is also increased and accompanies the process of protein glycation has not been so far unambiguously proven in diabetic subjects.

In the present study; we determined the influence of diabetes on erythrocyte membrane fluidity and on the cholesterol to phospholipid molar ratio in erythrocyte membranes and in plasma lipoproteins. We also compared the extent of non-enzymatic glycation and accumulation of lipid peroxidation products in erythrocyte membranes and apoproteins of low density lipoproteins and high density lipoproteins in diabetic and control subjects, in order to determine the influence of possible chemical modifications of proteins on red blood cell membrane dynamics.

\section{Materials and Methods}

Subjects

Nineteen non-fasting diabetic patients (13 men: 11 type $I$ insulin-dependent, 2 type II non-insulin-dependent; 6 women: 5 type I, 1 type II with a mean \pm SD age of $36 \pm 10$ years (range $23-53)$ and 19 age- (36 \pm 10 years, range $22-57)$ and sexmatched control subjects were studied. Mean body weights were not significantly different between control $(70.7 \pm 11.9 \mathrm{~kg})$ and diabetic $(71.4 \pm 10.0 \mathrm{~kg})$ subjects. Mean duration of diabetes was $18 \pm 9$ years. Of the diabetic subjects, 17 had been treated with insulin alone and 2 had been treated with diet and an oral hypoglycaemic agent (Glyburide). None of the diabetic or control subjects was treated with any normolipidaemic medication. Two diabetic subjects had retinopathy, 1 had angina pectoris and 3 had hypertension. Blood was collected from each diabetic subject and the paired control subject on the same day. These studies were approved by the Committee on the Ethics of Research in Human Experimentation at McMaster University.
Blood collection and preparation of erythrocyte membranes

Blood $(100 \mathrm{ml})$ was collected into a plastic syringe from a forearm vein through an 18 gauge needle. Fourteen millilitres of this blood were added to EDTA-containing vacutainer tubes (Becton Dickinson, Missisauga, Ontario, Canada) for determination of $\mathrm{HbA}_{\mathrm{ic}}$ and glucose concentration of the plasma. The remaining blood was anticoagulated with acid-citrate-dextrose solution (1 ACD + 6 blood, vol/vol) and used for preparation of erythrocyte membranes. Red blood cells washed four times with phosphate-buffered saline $\mathrm{pH} 7.4$ were subjected to moderate haemolysis in Tris-HCl/EDTANa ${ }_{2}$ buffer $\mathrm{pH} 7.0$ according to Marchesi \& Palade (14). The isolated erythrocyte membranes were resuspended in ice-cold phosphate-buffered saline with phenylmethylsulphonyl fluoride, sodium azide and EDTANa $_{2}$. The protein content in erythrocyte membrane suspensions was measured according to the modified method of Lowry et al. (15). The membrane suspensions were subsequently used for determination of membrane fluidity, cholesterol, phospholipid, lipid peroxidation and non-enzymatic glycation of membrane protein. The samples from diabetic and control subjects were obtained, stored and analysed at the same time and under the same conditions.

Isolation of low-density lipoproteins and high-density lipoproteins from plasma

In order to inhibit protease and lipase activities, plasma was supplemented with $100 \mathrm{ml} / 1$ of a solution containing phenylmethylsulphonyl fluoride ( $2 \mathrm{mmol} / \mathrm{l}), \mathrm{EDTANa}_{2}(1 \mathrm{mmol} / \mathrm{l})$, sodium azide $(2 \mathrm{mmol} / \mathrm{l})$. High density lipoproteins were separated from low density lipoproteins by the precipitation of the latter using a combination of sodium phosphotungstate and magnesium chloride (16), after prior separation of very low density lipoproteins according to Schriewer et al. (17). Low density lipoproteins and high density lipoproteins were purified according to Mills et al. (16) and extensively dialysed against phosphate-buffered saline with phenylmethylsulphonyl fluoride/EDTANa $/ \mathrm{NaN}_{3}$ pH 7.2 at $4{ }^{\circ} \mathrm{C}$. Ten microlitres of $\beta$ hydroxytoluene in methanol $(0.1 \mathrm{~mol} / \mathrm{l})$ were added per $1 \mathrm{ml}$ of lipoprotein solutions to protect samples from spontaneous peroxidation, and the samples were stored at $-70^{\circ} \mathrm{C}$ until assayed.

\section{Fluidity measurements}

Erythrocyte membrane fluidity was determined by measuring fluorescence polarization (18) with the hydrophobic probe 1,6diphenyl-1,3,5-hexatriene (Molecular Probes, Eugene, OR, USA; $0.5 \mathrm{mmol} / 1$ in tetrahydrofuran). 1,6-Diphenyl-1,3,5-hexatriene was diluted $1: 100$ in phosphate buffered saline, $\mathrm{pH} 7.4$, and vigorously mixed immediately before use. One volume of this diluted 1,6-diphenyl-1,3,5-hexatriene dispersion was added to 1 vol of the erythrocyte membrane suspension containing $0.2 \mathrm{~g} / 1$ protein, and the mixture was incubated at $37^{\circ} \mathrm{C}$ for 35 min. The final protein concentration was $0.1 \mathrm{~g} / \mathrm{l}$.

Steady-state fluorescence polarization was measured at $37^{\circ} \mathrm{C}$ with a Perkin-Elmer spectrofluorometer equippped with polarizers in the excitation and emission beams. The excitation and emission wavelengths were 360 and $430 \mathrm{~nm}$, respectively. Fluorescence polarization was determined using a standard formula from emission intensities that were polarized parallel and perpendicular to the direction of the polarized excitation (18). The grating transmission factor of Chen \& Bowman (19) was used to correct for the depolarization effect of grating monochromators (20). A fluorescence intensity value for a nonlabelled blank was subtracted as a correction for scattered light. Fluorescence polarization values mainly reflect lipid structural order, and lipid fluidity has been defined as the reciprocal of the lipid structural order parameter (21). 


\section{Measurement of cholesterol and phospholipids}

Samples of the erythrocyte membrane suspensions containing $100-200 \mu \mathrm{g}$ protein were subjected to lipid extraction using a two-step extraction procedure with neutral solvent (chloroform : methanol, $1+2$, vol/vol) and acidic solvent (chloroform : methanol: $\mathrm{HCl}$ : water, $3+4+0.5+0.1$, vol/vol) (22). The lipid extracts were dried under nitrogen and lipid residues were re-dissolved in chloroform $(1 \mathrm{ml})$. The cholesterol content of lipid extracts of erythrocyte membranes was determined by the cholesterol oxidase fluorometric assay (23), and phosphorus was measured using ammonium molybdate and ascorbic acid after mineralization with magnesium nitrate (24).

\section{Measurement of glycation}

The extent of glycation was determined as described earlier (25). Aliquots of erythrocyte membranes or isolated lipoproteins containing $100 \mu \mathrm{g}$ or $2 \mathrm{mg}$ protein, respectively, were treated with equal volumes of $24 \mathrm{mmol} / \mathrm{l}$ sodium borohydride$\left[{ }^{3} \mathrm{H}\right]$ (New England Nuclear, Mississauga, Ontario, Canada; 3.7 $\mathrm{TBq} / \mathrm{mol}=100 \mathrm{mCi} / \mathrm{mmol}$ ) and incubated at $37^{\circ} \mathrm{C}$ for $2 \mathrm{~h}$. After incubation, $30 \mathrm{~g} / \mathrm{l}$ bovine serum albumin was added to each sample and the protein precipitated with $100 \mathrm{~g} / \mathrm{l}$ trichloroacetic acid. The pellet was dissolved in $1 \mathrm{~mol} / \mathrm{l} \mathrm{NaOH}$ and reprecipitated with trichloroacetic acid. This procedure was repeated 4-5 times until no further radioactivity could be detected in the supernatant. Radioactivity was measured in the final pellet redissolved in $1 \mathrm{~mol} / 1 \mathrm{NaOH}$. Results were expressed in nmol glucose assuming that $1 \mathrm{~mol}$ of glucose moiety adduct is reduced by $1 \mathrm{~mol}$ of sodium borohydride- $\left[{ }^{3} \mathrm{H}\right]$.

Determination of $\mathrm{HbA}_{1 c}$ and plasma glucose concen trations

$\mathrm{HbA}_{1 \mathrm{c}}$ was determined in whole blood using a glycoaffinity column (26) (the normal range of $\mathrm{HbA}_{1 \mathrm{c}}$ is $4.5 \%-7.5 \%$ ). Plasma glucose was measured by the glucose oxidase method with an Ektachem (Eastman-Kodak, Rochester, NY, USA) (27).

\section{Measurement of lipoperoxidation products}

The products of lipid peroxidation in erythrocyte membranes and in plasma lipoproteins were determined according to the method of Wong et al. (28) with modifications. In principle, the adduct of malondialdehyde with 2-thiobarbituric acid was sep- arated from interfering chromogens on the HPLC column and lipoperoxide concentrations were computed by reference to a calibration curve prepared by assaying tetraethoxypropane. Before addition of thiobarbituric acid reagent the incubation mixture was supplemented with $\beta$-hydroxytoluene and the solubilizing agent, polyoxyethylene ether W-1 (29) (Sigma Chemical Co.), at the final concentrations of $3 \mathrm{mmol} / \mathrm{l}$ and $1 \mathrm{~g} / \mathrm{l}$, respectively. The amounts of lipoperoxides were expressed in $\mathrm{nmol}$ of thiobarbituric acid reacting substance.

\section{Analysis of data}

Means \pm SD are given. Paired $t$ tests (2-tailed) were used to determine the significance of differences. The normal distribution of data was confirmed using the Shapiro-Wilk's test (30). A combined test for correlation coefficients was performed to assess the relationships among the quantities investigated (31).

\section{Results}

The mean plasma glucose and $\mathrm{HbA}_{1 \mathrm{c}}$ were significantly greater in diabetic patients than in control subjects $(2.12 \pm 0.96 \mathrm{~g} / 1$ vs $0.84 \pm 0.16 \mathrm{~g} / \mathrm{l}$, $\mathrm{p}<0.001$, and $12.5 \% \pm 3.0 \%$ vs $5.8 \% \pm 0.5 \%$, $\mathrm{p}<0.001$, respectively).

The mean steady-state fluorescence polarization value of 1,6-diphenyl-1,3,5-hexatriene in isolated erythrocyte membranes from diabetic subjects $(0.186$ $\pm 0.008, n=14)$ was significantly greater than that for control subjects $(0.173 \pm 0.006, \mathrm{n}=14$, $\mathrm{p}<0.001)$. The lipid contents of erythrocyte membranes and of low-density lipoproteins and high-density lipoproteins are shown in table 1 . The amount of cholesterol and the cholesterol to phospholipid molar ratio were significantly higher in isolated erythrocyte membranes from diabetic subjects compared with control subjects, but the phospholipid contents were similar. In plasma low-density lipoproteins from di-

Tab. 1. Cholesterol and phospholipid contents of erythrocyte membranes and of plasma low-density lipoproteins and high-density lipoproteins from diabetic and control subjects.

Diabetic Control $\quad \begin{aligned} & \text { Significance } \\ & \text { of difference }\end{aligned}$

$\mathrm{p}<$

Erythrocyte membranes

Cholesterol ( $\mu \mathrm{mol} / \mathrm{mg}$ protein)

Phospholipid ( $\mu \mathrm{mol} / \mathrm{mg}$ protein)

Cholesterol/phospholipid molar ratio

$0.827 \pm 0.063$

$0.571 \pm 0.077$

$0.453 \pm 0.049$

$0.830 \pm 0.085$

$0.551 \pm 0.080$

0.04

LDL

Cholesterol ( $\mu \mathrm{mol} / \mathrm{mg}$ protein)

Phospholipid ( $\mu \mathrm{mol} / \mathrm{mg}$ protein)

Cholesterol/phospholipid molar ratio

$5.33 \pm 0.72$

$1.17 \pm 0.20$

$4.67 \pm 0.87$

$4.73 \pm 0.47$

$1.34 \pm 0.14$

$3.56 \pm 0.57$

ns

HDL

Cholesterol ( $\mu \mathrm{mol} / \mathrm{mg}$ protein)

Phospholipid ( $\mu \mathrm{mol} / \mathrm{mg}$ protein)

$1.09 \pm 0.15$

$0.56 \pm 0.09$

Cholesterin/phospholipid molar ratio

$2.02 \pm 0.41$

$1.12 \pm 0.15$

$0.65 \pm 0.05$

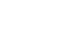

Values are means \pm SD for 14 subjects in each group. 
abetic subjects, the concentration of cholesterol was signficiantly higher $(\mathrm{p}<0.025)$, and that of phospholipid significantly lower $(p<0.025)$ than the corresponding values for control subjects. In the plasma high density lipoproteins, the cholesterol content was not significantly different between groups, whereas the amount of phospholipids was significantly lower $(p<0.035)$ in diabetic subjects compared with control subjects. As a result of these differences in low density lipoproteins and high density lipoproteins, the cholesterol to phospholipid molar ratios were significantly higher in low density lipoproteins $(\mathrm{p}<0.001)$ and high density lipoproteins $(\mathrm{p}<0.02)$ from diabetic subjects compared with control subjects.

The amounts of non-enzymatically attached glucose were significantly increased, both in erythrocyte membranes $(\mathrm{p}<0.001)$ and in plasma low-density lipoproteins $(\mathrm{p}<0.001)$ and high-density lipoproteins $(\mathrm{p}<0.015)$ from diabetic subjects compared with control subjects (tab. 2); the most significant differences occurred in erythrocyte membranes.

The levels of thiobarbituric acid reacting substances, which are the hallmark of lipid peroxidation, were

Tab. 2. The extent of non-enzymatic glycation of proteins in erythrocyte membranes and in plasma low density lipoproteins and high density lipoproteins from diabetic and control subjects.

\begin{tabular}{llll}
\hline & Diabetic & Control & $\begin{array}{l}\text { Significance } \\
\text { of difference } \\
\text { p < }\end{array}$ \\
\hline Erythrocyte membranes (nmol glucose/mg protein) & $25.63 \pm 3.49$ & $21.23 \pm 2.78$ & 0.001 \\
LDL (nmol glucose/mg protein) & $29.05 \pm 4.53$ & $22.19 \pm 2.83$ & 0.001 \\
HDL (nmol glucose/mg protein) & $34.23 \pm 3.71$ & $29.72 \pm 4.67$ & 0.015 \\
\hline
\end{tabular}

Values are means \pm SD for $13-14$ subjects in each group.

Tab. 3. Lipoperoxide adducts in erythrocyte membranes and plasma low density lipoproteins and high density lipoproteins from diabetic and control subjects in nmol of thiobarbituric acid reactive substance per $\mathrm{mg}$ of protein.

\begin{tabular}{llll}
\hline & Diabetic & Control & $\begin{array}{l}\text { Significance } \\
\text { of difference } \\
\mathrm{p}<\end{array}$ \\
\hline Erythrocyte membranes & $4.17 \pm 0.91$ & $2.97 \pm 0.81$ & 0.025 \\
LDL & $0.241 \pm 0.035$ & $0.207 \pm 0.020$ & 0.01 \\
HDL & $0.217 \pm 0.056$ & $0.204 \pm 0.047$ & 0.03 \\
\hline
\end{tabular}

Values are means \pm SD for 11 subjects in each group.

Tab. 4. Correlation coefficients among the quantities examined in diabetic and control subjects.

\begin{tabular}{|c|c|c|}
\hline Quantity & $\begin{array}{l}\text { Correlation } \\
\text { coefficient } \\
\text { (r) }\end{array}$ & $\begin{array}{l}\text { Significance } \\
\text { of } \\
\text { correlation }\end{array}$ \\
\hline \multicolumn{3}{|l|}{ Erythrocyte membrane fluorescence polarization: } \\
\hline vs non-enzymatic glycation of erythrocyte membrane proteins & 0.399 & $\mathrm{p}<0.04$ \\
\hline vs lipid peroxidation in erythrocyte membranes & 0.551 & $\mathrm{p}<0.008$ \\
\hline vs cholesterol content in erythrocyte membranes & 0.363 & $\mathrm{p}<0.05$ \\
\hline vs cholesterol/phospholipid (molar ratio) in LDL & 0.590 & $\mathrm{p}<0.003$ \\
\hline vs cholesterol/phospholipid (molar ratio) in HDL & 0.371 & $\mathrm{p}<0.05$ \\
\hline \multicolumn{3}{|l|}{ Non-enzymatic glycation of LDL: } \\
\hline vs lipid peroxidation in LDL & 0.789 & $\mathrm{p}<0.003$ \\
\hline vs phospholipid content in LDL & -0.408 & $\mathrm{p}<0.03$ \\
\hline vs cholesterol/phospholipid (molar ratio) in LDL & 0.476 & $\mathrm{p}<0.015$ \\
\hline \multicolumn{3}{|l|}{ Erythrocyte cholesterol content: } \\
\hline vs cholesterol content in LDL & 0.381 & $\mathrm{p}<0.05$ \\
\hline vs non-enzymatic glycation of HDL & 0.372 & $\mathrm{p}<0.05$ \\
\hline \multicolumn{3}{|l|}{ Lipid peroxidation in LDL: } \\
\hline vs lipid peroxidation in erythrocyte membranes & 0.613 & $\mathrm{p}<0.03$ \\
\hline vs cholesterol content in LDL & 0.479 & $\mathrm{p}<0.035$ \\
\hline
\end{tabular}

Correlation coefficients are determined from 11-14 diabetic and 11-14 control subjects. 
increased in erythrocyte membranes and plasma lipoproteins in diabetics subjects; the most highly significant increase was observed in low-density lipoproteins $(\mathrm{p}<0.01)$ (tab. 3).

The degrees of correlation between the various quantities examined were determined for diabetic and control subjects (tab. 4). Fluorescence polarization values in erythrocyte membranes significantly correlated with the extent of non-enzymatic glycation, lipid peroxidation and the cholesterol content in these membranes and also with the cholesterol to phospholipid molar ratios in plasma low density lipoproteins and high-density lipoproteins. In low density lipoproteins the extent of non-enzymatic glycation significantly correlated with peroxidation and the cholesterol to phospholipid molar ratio and inversely correlated with the phospholipid content. The cholesterol content of erythrocyte membranes significantly correlated with the cholesterol content in low density lipoproteins and the extent of non-enzymatic glycation in high density lipoproteins. Lipid peroxidation in low density lipoproteins significantly correlated with lipid peroxidation in erythrocyte membranes and with the cholesterol content in low density lipoproteins. Other correlations were not statistically significant.

\section{Discussion}

The results from the present study show that, compared with erythrocyte membranes from controls, erythrocyte membranes from diabetic subjects display reduced membrane lipid fluidity, together with the increase in membrane protein glycation, lipid peroxidation, and the cholesterol to phospholipid molar ratio. Furthermore, low density lipoproteins and high density lipoproteins from diabetic subjects were more extensively glycated, had a higher cholesterol to phospholipid molar ratio, and contained greater amounts of lipid peroxidation products than those from control subjects. The extent of non-enzymatic glycation correlated with the extent of lipid peroxidation and the cholesterol to phospholipid molar ratio in low density lipoproteins from diabetic and control subjects, but this correlation was not evident in high density lipoproteins or erythrocyte membranes. The values for membrane lipid fluidity in erythrocytes from diabetic and control subjects inversely correlated with the cholesterol to phospholipid molar ratios in low density lipoproteins and high density lipoproteins.

In our recent study, conducted within the same population of patients, we also found a significant inverse correlation between membrane lipid fluidity and the extent of non-enzymatic glycation of membrane pro- teins in platelets from diabetic and control subjects, although the cholesterol to phospholipid molar ratio did not differ between platelets from diabetic and control subjects (13). It seems reasonably certain, therefore, to conclude that red blood cells are not unique with respect to the rigidization of the membrane lipid bilayer due to the increased membrane protein glycation in the diabetic state. In platelets, non-enzymatic glycation of membrane proteins also results in the rigidification of the lipid bilayer.

Non-enzymatic glycation of low density lipoproteins has been reported to alter the binding of low density lipoproteins to platelets and to various other cell types $(32,33)$. In some diabetics the level of glycation may be sufficient to interfere with the normal metabolism of low density lipoproteins (25). The extent of the glycation of low density lipoproteins in diabetic juveniles has been previously reported to correlate with lipid composition of low density lipoproteins and the cholesterol to phospholipid molar ratio in erythrocyte membranes. These changes seemed to invoke the alterations in membrane lipid bilayer dynamics in erythrocytes from diabetic subjects (12). Thus, non-enzymatic glycation of erythrocyte membrane proteins seems to be of major importance in the impairment of red blood cell functions; additionally it appears to be involved in the augmentation of the rate of postsynthetic modifications of plasma low density lipoproteins. Increased glycation of low density lipoproteins, either in vitro or in material isolated from diabetic subjects, may lead to impaired uptake by the classic low density lipoprotein receptor and the increased uptake by human monocyte-derived macrophages (for reviews see $(11,34)$ ). The former effect may increase circulating low-density lipoprotein concentrations, whereas the latter effect may contribute to foam cell formation, a precursor in the development of atherosclerosis $(9-11)$. Furthermore, a positive correlation between the degree of non-enzymatic glycation of low density lipoproteins and the enhancement of platelet aggregation has been demonstrated, and numerous data suggest that glycated low density lipoproteins may contribute to the hyperaggregability of platelets in diabetics (32).

In the present study, we found significantly increased cholesterol to phospholipid molar ratios in plasma low density lipoproteins and high density lipoproteins and in erythrocyte membranes from diabetic subjects, and these changes were inversely related to the membrane lipid fluidity of erythrocytes. Our present study demonstrates that erythrocyte membranes, as well as plasma low density lipoproteins and high density lipoproteins from diabetic subjects, contain increased 
levels of thiobarbituric acid reacting substances compared with control subjects. These changes were associated with a reduced membrane fluidity of erythrocytes from diabetic subjects compared with control subjects, which has been taken as evidence that lipid peroxidation may be essentially involved in the modification process $(35,36)$. The concept is supported by the significant inverse correlation found among erythrocyte membrane fluidity and the extent of lipid peroxidation in erythrocyte membranes and plasma low density lipoproteins and high density lipoproteins. This relation does not appear to have been examined previously, but the reduced erythrocyte membrane fluidity in the diabetic state is consistent with our earlier reports, in which we showed a reduced membrane fluidity in isolated erythrocyte membranes from diabetic adults and juveniles, and the alterations were found to relate both to the membrane lipid composition $(37,38)$ and to the extent of membrane protein glycation $(12,39)$.

It has been shown that native and oxidatively modified lipoproteins differ importantly in their effects on cells. The oxidized low density lipoproteins and high density lipoproteins are more reactive than the native ones, and they are thought to promote the vascular events which are characteristic of atherogenesis (2, 11). Our results show that the increased lipid peroxidation of erythrocyte membranes, low density lipoproteins and high density lipoproteins occurred in all but 1,2, and 3 diabetic subjects, respectively. With respect to this finding our results do not agree completely with the results of the studies published hitherto. There is no direct evidence that lipid peroxidation is increased in uncomplicated human diabetes $(40-42)$. With the exception of one report by Collier et al. (43), the evidence suggests that peroxidation of circulating plasma lipoproteins may not be related to diabetes itself, but rather to the underlying diabetic complications.

The positive correlation between the extent of glycation and thiobarbituric acid reacting substances level is not obscure, since the process of non-enzymatic glycation has been postulated to augment free radical formation. This phenomenon may be of particular importance in diabetic patients, where the sources of free oxygen radicals are augmented by the increased glycation of proteins, so that natural defences may be overwhelmed $(35,36)$.

The formation of reactive aldehydes is known to impair the physical properties and the flexibility of red blood cell membranes (44). This seems to be the case in the present study, as we found a very significant inverse correlation between erythrocyte membrane fluidity and the extent of erythrocyte membrane lipid peroxidation.

The above reported observations suggest the potential importance of glycated and oxidized low density lipoproteins in the pathogenesis of atherosclerosis and adds a new dimension to the relationship between plasma lipoproteins and blood cell membranes in diabetes, as well as implying a potential role of altered lipoproteins in the pathogenesis of atherosclerosis.

\section{Acknowledgement}

This study was supported by grants-in-aid from the Heart and Stroke Foundation of Ontario (T-1171). PDW was a Research Scholar of the Heart and Stroke Foundation of Canada.

We are grateful to $B$. Ross-Ouellet and D. Perry for technical assistance. We also thank Dr. C. J. Toews and the staff of Diabetic Day Care for providing access to diabetic patients.

\section{References}

1. Nikkila, E. A. (1984) Plasma lipid and lipoprotein abnormalities in diabetes. In: Diabetes and heart disease (Jarrett, P., ed.) Amsterdam - New York-Oxford, Elsevier Science Publishers BV, pp. 133-167.

2. Colwell, J. A., Winocour, P. D., Lopes-Virella, M. (1990) Platelet function and platelet-plasma interactions in atherosclerosis and diabetes mellitus. In: Diabetes Mellitus, Theory and Practice (Rifkin, H. \& Porte, D., eds.) New York, Elsevier, pp. 249-256.

3. Kraemer, F. B. (1987) Diabetes and lipoprotein receptors. Diab. Metab. Rev. 3, 591-618.

4. Shinitzky, M. (1984) Membrane fluidity and cellular functions. In: Physiology of Membrane Fluidity (Shinitzky, M., ed.) vol. 1, CRC Press, Boca Raton, pp. 1-43.

5. Garnier, M., Attali, J. R., Valensi, P., Delatour-Hanss, E., Gaudey, F. \& Koutsouris, D. (1990) Erythrocyte deformability in diabetes and erythrocyte membrane lipid composition. Metabolism 39, 794-798.
6. Winocour, P. D. (1989) The role of platelets in the pathogenesis of diabetic vascular disease. In: Complications of Diabetes Mellitus. Molecular and Cellular Biology of Diabetes Mellitus (Draznin, B., Melmed, S. \& LeRoith, D., eds.) vol. III, New York, Alan R. Liss Inc., pp. 37-47.

7. Lyons, T. J., Patrick, J. S., Baynes, J. W., Colwell, J. A. \& Lopes-Virella, M. F. (1986) Glycation of low density lipoprotein in patients with Type 1 diabetes: Correlations with other parameters of glycaemic control. Diabetologia 29, $685-689$.

8. Cerami, A., Vlassara, H. \& Brownlee, M. (1988) Advanced products of nonenzymatic glycosylation and the pathogenesis of diabetic vascular disease. Diab. Metab. Rev. 4, 437451 .

9. Steinbrecher, U. P. \& Witztum, J. L. (1984) Glucosylation of low density lipoproteins to an extent comparable to that seen in diabetes slows their catabolism. Diabetse 33,130134. 
10. Steinberg, D., Parthasarathy, S., Carew, T. E., Khoo, J. C. \& Witztum, J. L. (1989) Beyond cholesterol-modifications of low-density lipoprotein that increase its atherogenicity. N. Engl. J. Med. 320, 915-924.

11. Jurgens, G., Hoff, H. F., Chisolm, III G. M. \& Esterbauer, H. (1987) Modifocation of human serum low density lipoprotein by oxidation - characterization and pathophysiological implications. Chem. Phys. Lipids 45, 315-336.

12. Watala, C. \& Kordacka, M. (1987) Nonenzymatic glycosylation of proteins. II. Does glycosylation of low density lipoproteins affect lipid composition of erythrocyte membranes. Ann. Clin. Res. 19, 194-197.

13. Winocour, P. D., Watala, C. \& Kinlough, Rathbone, R. L. (1992) Membrane fluidity is related to the extent of glycation of proteins, but not to alterations in the cholesterol to phospholipid molar ratio in isolated platelet membranes from diabetic and control subjects. Thromb. Haemost. (in press).

14. Marchesi, V. T. \& Palade, G. E. (1967) The localization of $\mathrm{Mg}-\mathrm{Na}-\mathrm{K}$-activated adenosine triphosphatase on red blood cell membranes. J. Cell Biol. 35, 385-404.

15. Lowry, O. H., Rosenbrough, N. J., Farr, A. L. \& Randall, R. J. (1951) Protein measurement with the Folin phenol reagent. J. Biol. Chem. 193, 265-275.

16. Mills, G. L., Lane, P. A. \& Weech, P. K. (1984) A Guidebook to Lipoprotein Technique Serie: Laboratory Techniques. In: Biochemistry and Molecular Biology (Burdon, R. H. \& van Knippenberg, P. H., eds.) vol. 14, Amsterdam-New York-Oxford, Elsevier Science Publishers BV, pp. 90-96.

17. Schriewer, H., Kohnert, U. \& Assmann, G. (1984) Determination of LDL cholesterol and LDL apoprotein B following precipitation of VLDL in blood serum with phosphotungstic acid $/ \mathrm{MgCl}_{2}$. J. Clin. Chem. Clin. Biochem. 22, 35-40.

18. Shinitzky, M. \& Barenholz, Y. (1978) Fluidity parameters of lipid regions determined by fluorescence polarization. Biochim. Biophys. Acta 515, 367-394.

19. Chen, R. F. \& Bowman, R. L. (1985) Fluorescence Polarization measurement with ultra-polarizing filters in a spectrophotofluorometer. Science 147, 729-732.

20. Azumi, T. \& McGlynn, S. P. (1962) Polarization of the luminescence of phenanthrene. J. Chem. Phys. 37, 24132420.

21. Van Blitterswijk, W. J., Hoeven, R. P. \& Van der Meer, B. W. (1981) Lipid structural order parameters reciprocal of fluidity in biomembranes derived from steady-state fluorescence polarization measurements. Biochim. Biophys. Acta 644, 323-332.

22. Vickers, J. D. \& Rathbone, M. P. (1979) The effect of membrane cholesterol depletion upon erythrocyte membrane-bound proteins. Can. J. Biochem. 57, 1144-1152.

23. Gamble, W., Vaughan, M., Kruth, H. S. \& Avigan, J. (1978) Procedure for determination of free and total cholesterol in micro- and nanogram amounts suitable for studies with cultured cells. J. Lipid. Res. 19, 1068-1070.

24. Ames, B. N. (1966) Assay of inorganic phosphate, total phosphate and phosphites. Meth. Enzymol. 8, 115-118.

25. Witztum, J. L., Mahoney, E. M., Branks, M. J., Fisher, M., Elam, R. \& Steinberg, D. Nonenzymatic glucosylation of low-density lipoprotein alters its biologic activity. Diabetes $31,283-291$.

26. Allen, D. W., Schroeder, W. A. \& Balog, J. (1958) Observation on chromatographic heterogeneity of normal adult and fetal haemoglobin. Chem. Soc. Rev. 80, 1628-1634.

27. Kadish, A. H., Little, R. L. \& Sternberg, J. C. (1968) A new and rapid method for the determination of glucose by measurement of rate of oxygen consumption. Clin. Chem. $14,116-131$.
28. Wong, S., Knight, J. A., Hopfer, S. M., Zaharia, O., Leach, C. N. Jr. \& Sunderman, F. W. Jr. (1987) Lipoperoxides in plasma as measured by liquid-chromatographic separation of malondialdehyde-thiobarbituric acid adduct. Clin. Chem. 33, 214-220.

29. Morisaki, N., Lindsey, J. A., Stitts, J. M., Zhang, H. \& Cornwell, D. G. (1984) Fatty acid metabolism and cell proliferation. V. Evaluation of pathways for the generation of lipid peroxides. Lipids 19, 381-394.

30. Zar, J. (1984) Biostatistical analysis. Englewood Cliffs, NJ, Prentice-Hall.

31. Siegel, S. \& Castellan, N. J. Jr. (1988) Nonparametric statistics for the behavioral sciences. New York, McGraw-Hill Book Company.

32. Watanabe, J., Wohltmann, H. J., Klein, R. L., Colwell, J. A. \& Lopes-Virella, M. F. (1988) Enhancement of platelet aggregation by low density lipoproteins from IDDM patients. Diabetes 37, 1652-1657.

33. Klein, R. L., Lopes-Virella, M. F. \& Colwell, J. A. (1990) Enhancement of platelet aggregation by the glycosylated subfraction of low density lipoprotein (LDL) isolated from patients with insulin-dependent diabetes mellitus (IDDM) (Abstract) Diabetes 39 (suppl. 1), 173.

34. Lyons, T. J. (1991) Oxidized low density lipoproteins: a role in the pathogenesis of atherosclerosis in diabetes? Diab. Med. 8, 411-419.

35. Gillery, P., Monboisse, J. C., Maquart, F. X. \& Borel, J. P. (1989) Does oxygen free radical increased formation explain long term complications of diabetes mellitus. Med. Hypotheses $29,47-50$.

36. Wolff, S. P. \& Dean, R. T. (1987) Glucose autooxidation and protein modification: the potential role of 'autooxidative glycosylation' in diabetes mellitus. Biochem. J. 245, $243-250$

37. Watala, C., Kordacka, M., Loba, A., Jóźwiak, Z. \& Nowak, S. (1987) Analysis of membrane fluidity changes and lipid disorders in type 1 diabetic children and adolescents. Acta Diabetol. Lat. 24, $141-148$.

38. Bryszewska, M., Watała, C. \& Torzecka, W. (1986) Changes in fluidity and composition of erythrocyte membranes and in composition of plasma lipids in type I diabetes. British J. Haematol. 62, 111-116.

39. Watala, C., Zawodniak, M., Bryszewska, M. \& Nowak, S. (1985) Nonenzymatic protein glycosylation. I. Lowered erythrocyte membrane fluidity in juvenile diabetes. Ann. Clin. Res. 17, 327-330.

40. Nishigaki, I., Hagihara, M., Tsunekawa, H., Maseki, M. \& Yagi, K. (1981) Lipid peroxide levels of serum lipoprotein fractions of diabetic patients. Biochem. Med. 25, 373-378.

41. Kaji, H., Kurasaki, M. \& Ito, K. (1985) Increased lipoperoxide value and glutathione peroxidase activity in blood plasma of type 2 (non-insulin-dependent) diabetic women. Klin. Wochenschr. 63, 765-768.

42. Jennings, P. E., Jones, A. F., Florkowski, C. M., Lunec, J. \& Barnett, A. H. (1987) Increased diene conjugates in diabetic subjects with microangiopathy. Diabetic Med. 4, $452-456$

43. Collier, A., Jackson, M., Dawkes, R. M., Bell, D. \& Clarke, B. F. (1988) Reduced free radical activity detected by decreased diene conjugates in insulin-dependent diabetic patients. Diabetic Med. 5, 747-749.

44. Tozzi-Cianciarelli, M. G., d'Alfonso, A., Tozzi, E., TroianiSevi, E. \& de Matters, G. (1989) Fluorescence studies of aged erythrocyte membranes. Cell. Mol. Biol. 35, 113120.

Dr. Cezary Watala

Department of Biophysics

University of Lodz

ul. Banacha 12/16

90-237 Lodz

Poland 


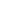

